\title{
Histological Studies of the Thyroid Gland of the Female Mouse in Relation to Lactation, Weaning and the Sexual Cycle ${ }^{1}$
}

\author{
By \\ Yasushi Aida \\ Department of Anatomy, Nagoya University School of Medicine \\ Nagoya, Japan \\ (Director: Prof. Dr. Shooichi Sugi y a ma) \\ With Ten Figures

\section{Introduction}

The relation existing between the thyroid gland and lactation has received much attention so far, but some controversy exists concerning the part which the thyroid gland plays in lactation. The role of the thyroid gland in lactation has been regarded as being minor on one hand, and no inhibition of lactation has been observed in thyroidectomized animals (D r a g s te d t et al., '24, dogs ; $\mathrm{N}$ e l s o n, '36, rats; Nels o $\mathrm{n}$ and Tob i n, '37, rats). But on the other hand, decreased milk secretion following thyroidectomy in goats was.observed by $\mathrm{Gr}$ i m me r ('18). It has been noted that the addition of dried thyroid to the diet of cows caused a rapid increase in the quantity of milk again ( $\mathrm{Graham}, 34 \mathrm{a}$ and b), while Folle y ('38) found that by giving suitable amounts of dried thyroid or by injecting thyroxine, the production of milk increased transiently to 30 per cent above the ordinary level, W e i c he r t and B o y d ('34) stated that mammary development is more rapid, and the secretory phase established earlier in pregnant rats receiving dried thyroid than in controls.

Notwithstanding such results having been published, systematic histological descriptions regarding the thyroid gland in the normal course of lactation is apparently scarce (cf. B a r g m a n n, '39), and this seems to call for a thorough investigation of the histological aspects of this problem.

1: This study was supported by a grant from the Department of Education. 
The present paper contains the observations of histological changes in the thyroid glands of mice during lactation and almost natural weaning, and those of mice forced to wean their sucklings immediately after parturition. Some evidence concerning the histological changes are presented here, and their possible significances are discussed in relation to lactation, and weaning. Furthermore, the thyroid gland is observed histologically in relation to the sexual cycle.

\section{Materials and Methods}

A total of 249 primiparous mice ranging in age from 45 to 65 days were used. These animals were divided approximately equally in number into two groups of lactation and weaning. The lactation group consisted of mother animals whose nurselings were decreased to four immediately after parturition and nursed until 25 days after parturition, and later weaned. The weaning group consisted of mother animals whose nurselings were all weaned immediately after parturition. Mother animals of both groups were killed at regular intervals of 24 hours after parturition. Immediately before sacrifice the vaginal smear test was made in all the animals of the weaning group and in some (chiefly 26 to 35 days after parturition) of the lactation group, to examine the condition of the estrous cycle (tables 1 and 2).

In addition, to prove again accurately the general trend of the first reappearance of the estrous cycle after parturition on mother animals, whose nurselings were weaned immediately after parturition, 20 animals were left to survive for daily vaginal smear tests.

Immediately after sacrifice, the thyroid glands were removed, with the trachea and esophagus, and fixed in $\mathrm{C}$ i a c c i o's fluid. The materials were imbedded in paraffin, sectioned at $6 \mu$ transversely and mounted serially. The sections were stained chiefly with $\mathrm{He} \mathrm{i-}$ $\mathrm{d}$ e $\mathrm{n}$ h a i n's iron hematoxylin, and some with $\mathrm{M}$ a y e r's hematoxylin and eosin.

The histometrical measurements of various components of the thyroid glands were made exclusively of the middle one-third of the lateral lobe. They will serve as good histological indices for determining the functional phases induced by lactation and weaning, and also by the sexual cycle, of the thyroid glands. In the graphs (figs: 1 to 4) each point represents the observation based upon one animal.

The frequency per square millimeter of occurrence of follicles over $50 \mu$ in diameter was calculated as follows: The number con- 


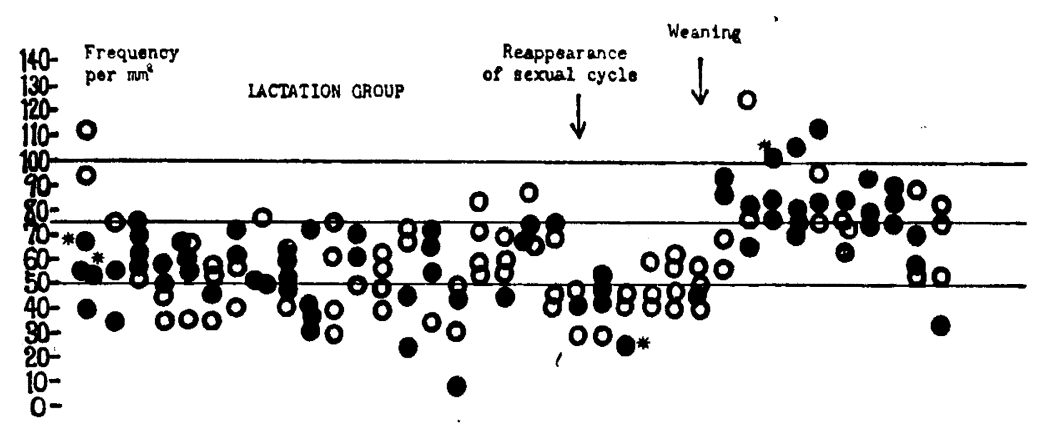

\section{5}

days after parturition

Fig. 1. Frequency averaged per square millimeter of follicles over $50 \mu$ in diameter in mouse females who nursed 4 children following parturition. Note: solid circle: a case showing a prevailing occurrence of secretory droplets in follicle epithelium; circles (open and solid) with an asterisk: a case whose histological picture is shown in plate figures.

tained within 20 sections consisting of every 5 th section was examined and the averaged number per square millimeter was determined by the ratio, frequency averaged per section/averaged section area (figs. 1 and 2). The diameters of follicles of over $50 \mu$ were obtained by adding. the length of the largest diameter and that of the diameter at right angles to it, and dividing the sum by 2 . The frequency per square millimeter of occurrence of irregular-shaped follicles was calculated in the same way.

To obtain some quantitative expression of serial changes of colloid, the following examination was made with Ciaccio-fixed prepara-

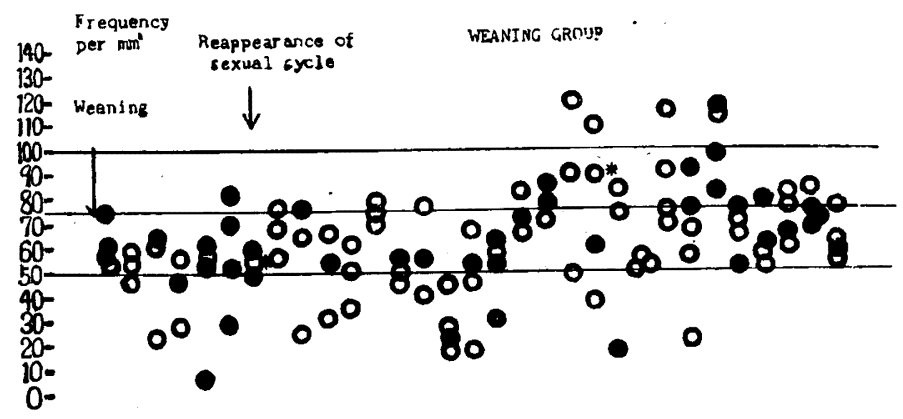

\section{0}

Fig. 2. Frequency averaged per square millimeter of follicles over $50 \mu$ in diameter in mouse females who were forced to wean their children immediately after parturition. 
tions stained by iron hematoxylin. An unevenness or spottiness of staining between the extremes (blue-black in the whole area within follicles and uniformly faintly gray) was for convenience reckoned as moderately stained colloid. In 20 fields of every 5 th sections, under low magnification (ocular $\times 8$, objective $\times 40$ ), follicles containing colloid of three staining orders, respectively, were counted. The total in each animal was averaged and the percentages of the three orders were derived. In the graphs (figs. 3 and 4), the percentages of follicles containing darkly stained colloid were plotted, and to avoid congestion of the graphs, the other two were omitted. The percentages do not represent the exact rates of colloid change, but

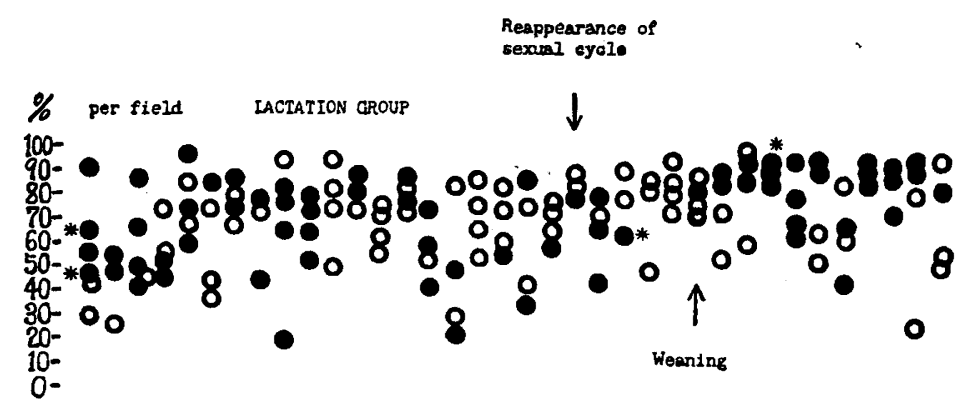

\section{5}

Fig. 3. Percentages averaged per field (ocular $\times 8$; objective $\times 40$ ) of the number of follicles containing darkly stained colloid in mouse females who nursed 4 children following parturition.

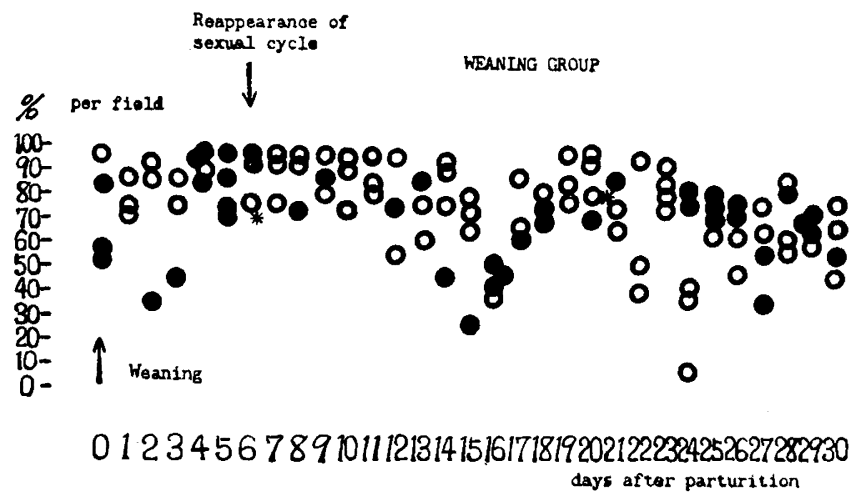

Fig. 4. Percentages averaged per field (occular $\times 8$; objective $\times 40$ ) of the number of follicles containing darkly stained colloid in mouse females who were forced to wean their children immediately after parturition. 
give an approximate indication of the colloid changes which are useful for criteria.

\section{Observations}

Follicles-The majority of large follicles were always located in the peripheral zone of the gland, and small follicles chiefly in the central zone, as were found in rats $(\mathrm{J} \mathrm{a} \mathrm{ck} \mathrm{son}, 16$; $\mathrm{Sug}$ i y a ma, '39) and mice ( $\mathrm{O}$ hid a, '54). Follicles were generally round to oval in shape. Irregular-shaped follicles which have been interpreted as a sign of increased thyroid activity, especially for the release of colloid (A r o n, '30, guinea pigs; S u g i y a m a, '39, rats; $\mathrm{S} u$ g i y a m a and $\mathrm{Y}$ a $\mathrm{g}$ i z a wa, '50, rabbits), were found relatively often.

Follicles over $50 \mu$ in diameter were regarded as large follicles, and as shown in figures 1 and 2, their frequency per square millimeter was plotted according to the progress of time after delivery. Based upon the examination of figures 1 and 2, four follicular types of the thyroid gland were classified as follows: microfollicular type (below 50 per square millimeter), macrofollicular type (over 100) and intermediate type subdivisible into transitionally microfollicular type (from 50 to below 75) and transitionally macrofollicular type (from 75 to below 100). The microfollicular type appeared to be characterized by an absolute predominance of follicles between 30 to $40 \mu$ in diameter, being admixed with very small follicles between 20 to $25 \mu$ (fig. 6). Detailed observations showed that, among these follicles there is a small number of large follicles between 50 and $70 \mu$ chiefly at the periphery of the gland. The macrofollicular type, in the majority of the cases examined, appeared to be characterized by an absolute prevalence of large follicles between 80 and $90 \mu$. This type sometimes contained a number of large follicles over $100 \mu$ which ranged in number per square millimeter from 5 to 11, and sometimes a large number of follicles measuring 50 to $70 \mu$. The largest follicles found in this type were occasionally $120 \mu$, the maximum value being $210 \mu$.

Lactation group: Immediately after parturition the frequency per square millimeter of follicles over $50 \mu$ appeared to decrease (figs. 1 and 5 ), and the frequency was maintained at almost the same state until weaning (until 25 days after parturition) (fig. 6). Most of the glands examined were found to be microfollicular or transitionally microfollicular in types. Immediately after weaning, the frequency 
per square millimeter of follicles over $50 \mu$ increased (figs. 1 and 7), and was maintained at almost the same state for a week but afterwards decreased in value.

Irregular-shaped follicles occurred in considerable numbers in the lactation group. Irregular-shaped follicles increased abruptly after weaning. Some of them indicated papillary projections of the follicle walls extending to the follicle cavity (fig. 7). Others showed elevated swellings of the follicle walls. Still others indicated various shapes such as dum-bells, star-fishes, arched and branching tubules.

Weaning group: The frequency per square millimeter of follicles over $50 \mu$ in diameter showed a decrease immediately after parturition, and was maintained in the same state until 16 days after parturition (figs. 2 and 8). During this period, most of the glands examined showed a microfollicular trend. After this period the glands became transiently of the macrofollicular type. Irregular-shaped follicles were more numerously found than in the lactation group, and especially after 16 days after parturition.

Follicles in relation to the sexual cycle: The frequency per square millimeter of follicles over $50 \mu$ was examined in relation to the estrous cycle of female mice after weaning in the lactation and weaning groups. Any significant differences were not found between the 4 different stages of the cycle (tables 1 and 2). In the lactation group, the diestrous stage showed an averaged,value of 72 per square millimeter, a value smaller than that in any of the other stages, which indicated averaged values of 87 to 81 . The range of individual values in each stage was very wide. In the weaning group, the diestrous stage was 58 , and the other three stages 68 to 62 . The range in each stage was also very wide in this group.

Follicle Cells-Follicle cells varied in height and form in different follicles and were so dependent upon age, glandular zone and length of the experiment. Nuclei of the general follicle cells were round to oval, and located somewhat centrally or basally in the cell body. The chromatin reticulum was moderately dense. A number of hyperchromatic nuclei whose chromatin reticulum was completely obscure with iron hematoxylin stain but not pyknotic, were often found. The cytoplasm was finely granular and its granularity of various degrees led follicle cells to assume different forms from clear swollen follicle cells to darkly stained cells. Some of the follicle cells were loaded with several or a few secretory droplets of various shades of black (fig. 10). The secretory droplets were found chiefly in the 
Table 1. Frequencies averaged per square millimeter of follicles over $50 \mu$ and percentages averaged per field (ocular: $\times 8$; Objective: $\times 40$ ) of the number of follicles containing darkly stained colloid in 4 stages of the sexual cycle in the weaning group.

\begin{tabular}{|c|c|c|c|c|}
\hline days after parturition & proestrus & estrus & metestrus & diestrus \\
\hline 2 & & & & $61(93)$ \\
\hline 2 & & & & $21(87)$ \\
\hline 3 & & & & $28(86)$ \\
\hline 3 & & & & $56(73)$ \\
\hline 3 & & & & $* 46(46)$ \\
\hline 4 & & & & * 5 (99) \\
\hline 4 & & & & $52(95)$ \\
\hline 4 & & & & *52 (98) \\
\hline 4 & & & & $* 66 \quad(89)$ \\
\hline 5 & & & & *27 (88) \\
\hline 5 & & & & *81 (98) \\
\hline 5 & & & & *70 (74) \\
\hline 5 & & & & *53 (70) \\
\hline 6 & $58(78)$ & & & *58 (96) \\
\hline 6 & & & & *48 (94) \\
\hline 7 & & & & $65(78)$ \\
\hline 7 & & & & $56(95)$ \\
\hline 7 & & & & $75(93)$ \\
\hline 8 & $24(100)$ & & $62(96)$ & *79 (75) \\
\hline 9 & & & $68(97)$ & *52 (88) \\
\hline 9 & & & & $32(80)$ \\
\hline 10 & & $64(72)$ & $34(90)$ & $51(97)$ \\
\hline 11 & & & & $68(81)$ \\
\hline 11 & & & & $78(97)$ \\
\hline 11 & & & & $69(85)$ \\
\hline 12 & & $42(93)$ & & $50(53)$ \\
\hline 12 & & $* 54(73)$ & & \\
\hline 13 & & $39(59)$ & & $77(77)$ \\
\hline 13 & & & & *57 (86) \\
\hline 14 & & & & $45(92)$ \\
\hline 14 & & & & $18(74)$ \\
\hline 14 & & $28(93)$ & & $* 25(48)$ \\
\hline 15 & $18(72)$ & $66(65)$ & & $47(78)$ \\
\hline 15 & & & & *51 (27) \\
\hline 16 & & $* 54(50)$ & & *64 (42) \\
\hline 16 & & & & $* 29(41)$ \\
\hline 16 & & & & $59(40)$ \\
\hline 17 & & *68 (62) & & $82(88)$ \\
\hline 17 & & & & $67(63)$ \\
\hline 18 & $* 82(69)$ & & $* 76(75)$ & $71(79)$ \\
\hline 19 & $120(99)$ & & & $87(78)$ \\
\hline 19 & & & & $49(81)$ \\
\hline 20 & $107(99)$ & *61 (70) & & $85(80)$ \\
\hline
\end{tabular}




\begin{tabular}{|c|c|c|c|c|}
\hline 2 & $32(91)$ & & & \\
\hline 2 & $83(73)$ & & *18 (85) & $72(65)$ \\
\hline 2 & & $52(38)$ & & 48 (51) \\
\hline 2 & & $48(94)$ & & \\
\hline 2 & $113(79)$ & $76(80)$ & $93(73)$ & $65(92)$ \\
\hline 2 & & $68(37)$ & $54(6)$ & *75 (81) \\
\hline 2 & & & & *90 (73) \\
\hline 2 & & & & $20(40)$ \\
\hline 2 & & 111 (62) & *114 (77) & $* 80 \quad(71)$ \\
\hline 2 & & & *96 (72) & \\
\hline 2 & & 71 (48) & & $65(62)$ \\
\hline 2 & & $* 73(74)$ & & *51 (71) \\
\hline $2^{\prime}$ & $51(75)$ & & & *61 (54) \\
\hline 2 & $57(61)$ & & *78 (36) & \\
\hline $2 \varepsilon$ & & & *64 (80) & $82(61)$ \\
\hline 2 & & & 、 & 80 (85) \\
\hline 2 & & & & $62(54)$ \\
\hline 2 & & $86(64)$ & *69 (66) & *66 (68) \\
\hline 2 & & & $* 70$ (64) & \\
\hline 3 & & & & *58 (52) \\
\hline 3 & $56(46)$ & & $60(68)$ & $79(77)$ \\
\hline averaged $\mathrm{v}$ & $67(78)$ & $62(67)$ & $68(70)$ & $58(75)$ \\
\hline
\end{tabular}

Note: *: A case with prevailing occurrence of secretory droplets in the follicle epithelium.

( ): Percentages averaged per field (ocular: $\times 8$; objective $\times 40$ ) of the number of follicles containing darkly stained colloid.

supranuclear zone and were of different sizes. Some of them attained diameters of two or three microns.

Mitotic figures of follicle cells were rarely found.

Lactation group: Until two days after parturition the follicle cells were highly swollen cubical in the central zone of the gland (fig. 5), and columnar in the peripheral zone. The cytoplasm was clear and much vacuolated. From three to 25 days after parturition the follicle cells were slightly decreased in height and became generally cubical (fig. 6), but sometimes swollen cubical in the central zone and columnar in the peripheral zone of the gland. Especially during a period from 20 to 25 days after parturition the follicle cells were usually swollen. After weaning (25 days after parturition) the follicle cells became more swollen with increased granularity in the cytoplasm.

Secretory droplets were found most frequently from immediately after parturition to 9 days (figs. 1, 3 and 10). Later, after weaning the droplets were again found in abundance. 
Table 2. Frequencies averaged per square millimeter of follicles over $50 \mu$ and percentages averaged per field (ocular: $\times 8$; objective $\times 40$ ) of the number of follicles containing darkly stained colloid in 4 stages of the sexual cycle after weaning in the lactation group.

\begin{tabular}{|c|c|c|c|c|}
\hline days after parturition & proestrus & estrus & metestrus & diestrus \\
\hline 26 & & & *92 (87) & $* 85$ \\
\hline 26 & & & & $67(53)$ \\
\hline 26 & & & & $55(72)$ \\
\hline 27 & *66 (99) & & & *78 (88) \\
\hline 27 & $124(98)$ & & & $75(61)$ \\
\hline$\Omega 8$ & & *85 (90) & & *99 (93) \\
\hline 28 & & & & $* 77$ (84) \\
\hline 29 & & *104 (97) & & *76 (79) \\
\hline 29 & & & & *70 (66) \\
\hline 29 & & & & *71 (69) \\
\hline 30 & *111 (97) & & $98(67)$ & $* 81(90)$ \\
\hline 30 & & & & $76(53)$ \\
\hline 31 & $73(63)$ & *82 (69) & & *63 (48) \\
\hline 31 & & 77 (83) & & \\
\hline 32 & & *75 (91) & & *68 (92) \\
\hline 32 & & *91 (83) & & \\
\hline 33 & *84 (87) & & & *88 (91) \\
\hline 33 & $* 72$ (75) & & & \\
\hline 34 & & & & *69 (95) \\
\hline 34 & & & & *53 (92) \\
\hline 34 & & $53(28)$ & & $88(82)$ \\
\hline 35 & $83(57)$ & & $54(53)$ & $72(99)$ \\
\hline 35 & & & & *35 (83) \\
\hline averaged value & $87(82)$ & $81(77)$ & $81(69)$ & $72(79)$ \\
\hline
\end{tabular}

Note: *: A case with prevailing occurrence of secretory droplets in the follicle epithelium.

( ): Percentages averaged per field (ocular: $\times 8$; objective $\times 40$ ) of the number of follicles containing darkly stained colloid.

Weaning group: From immediately after parturition to 16 days the follicle cells were generally swollen cubical in the whole area of the gland (fig. 8). Some of them were columnar from three to 7 days after parturition in the peripheral zone of the gland. The cytoplasm was generally granular, but in some cases slightly vacuolated. From 17 to 30 days after parturition the follicle cells became more swollen cubical.

Secretory droplets appeared less frequently than in the lactation group. The droplets were found relatively often from immediately after parturition to 9 days, from 15 to 18 days and from 24 to 29 days after parturition (figs. 2 and 4 ). 
Parafollicular Cells-The parafollicular cells (S u g i y a m a, '39, rats) were found relatively of ten in the lactation and weaning groups. They showed no significant differences in their occurrence in the two groups. Parafollicular cells were round to oval or polygonal, and appeared usually like parietal cells of the gastric gland. without bordering the follicle cavity directly. Their distribution was found to be in a considerable number of follicles central. The nuclei were round to oval and as large as or smaller than those of ordinary follicle cells, and the chromatin reticulum was moderately dense. The cytoplasm was darkly granulated and sometimes darkly homogeneous.

Colloid, in Ciaccio-fixed preparations stained with hematoxylin and eosin, was as a rule not granulated, eosinophilic and rarely partly eosinophilic and partly basophilic. The colloid was stained more intensely in the peripheral zone of the gland. With $\mathrm{He}$ ide $\mathrm{nh}$ a i n's iron hematoxylin, differences in staining were more distinct. Marginal vacuoles (Randvakuolen) of colloid show the appearance of artifacts by fixation, but their numerous occurrence may well bear a relation to the release of colloid, beause of their characteristic distribution under certain conditions $(\mathrm{K} \mathrm{rog} \mathrm{h}$ and $\mathrm{Ok} \mathrm{kels,} \mathrm{'33,} \mathrm{guinea}$ pigs; Severinghaus, '33, guinea pigs and monkeys; A ron, '34, guinea pigs; Florentin, F ontaine and $\mathrm{Hennequ}$ i n, '36, rabbits; S u gi y a m a, '39, rats; S u g i y a ma and $\mathrm{Sat}$ o, '54, guinea pigs). The marginal vacuoles occurred to a greater extent in feebly stained colloid than in darkly stained colloid, but their frequent occurrence was occasionally seen in large follicles containing dark colloid, which consisted of swollen cubical or columnar follicle cells. Crevices which are obviously artifacts made by cutting with the microtome knife but are related to the high density of colloid, were found in darkly stained colloid and infrequently in feebly stained colloid. Colloid contained desquamated follicle cells rarely.

With Ciaccio-fixed preparations stained by $\mathrm{H}$ e i d e $\mathrm{n} \mathrm{h}$ a i n's iron hematoxylin, examination of colloid in the lactation and weaning groups indicated the following findings (figs. 3 and 4).

In the lactation group, the colloid was stained somewhat more inconstantly than in the weaning group. Immediately after parturition the colloid was stained feebly (figs. 3 and 5). Follicles containing dark colloid were found on an average to 40 to 60 per cent per field. From 4 days after parturition the colloid increased in staining grade with some fluctuations, and follicles containg dark colloid increased to 60 to 80 per cent per field. After weaning (25 days after 
parturition) the colloid stained darkly for a while with the increase in frequency of follicles over $50 \mu$ (fig. 7), and became stained inconstantly again with the decrease of follicles over $50 \mu$ (figs. 1 and 3).

In the lactation group, marginal vacuoles were found numerously throughout the experimental period, especially immediately after parturition (fig. 5).

In the weaning group, immediately after parturition, the colloid was stained darkly in contrast with that observed in the lactation group (figs. 3 and 4). This state lasted until 11 days after parturition. The dark colloid prevailed over the whole gland (fig. 8). From 12 days after parturition on, feeble colloid increased in rate and reached the maximum at 16 days. Follicles containing dark colloid were 20 to 60 per cent per field. After this time the colloid increased in staining degree (fig. 9) but it was stained inconstantly again from 22 days after parturition on.

Marginal vacuoles of colloid were found to be relatively numerous at three to 4 days after parturition. During the experimental period the marginal vacuoles were found numerously at 16 to 18 days, in coincidence with the feeble staining of colloid, and again at 24 to 25 days.

Colloid in relation to the sexual cycle: No significant differences were found between the 4 stages of the cycle (tables 1 and 2). In the lactation and weaning groups, the colloid, however, was generally slightly feeble in staining in the two successive stages of the estrus and metestrus.

Connective Tissue-did not show any marked alterations in the lactation and weaning groups. The interlobular connective tissue originating from the glandular capsule was relatively distinct in the medial peripheral zone. Perifollicular connective tissue was derived from the interlobular and capsular connective tissues. These tissues contained a number of steatoblasts which had fatty droplets in great abundance.

Blood Vessels-In the lactation and weaning groups, all of the vascular patterns of the glands, except for capillary hyperemia, appeared nearly alike. The arteries ran within or beneath the capsule and most of them entered the interior of the gland from the medial peripheral zone along the interlobular connective tissue to ramify into smaller branches. Veins were accompanied by the arteries. Most of the veins were only composed of the delicate intima and adventitia, without muscle fibers. 
Capillary hyperemia varied in occurrence according to the progress of time elapsing after parturition in the lactation and weaning grops. Engorged capillaries became sinusoidal and very of ten bulged into the follicle walls, indenting their basal surfaces. This arranzement enhanced still further the intimacy of the capillary with the follicle epithelium.

In the lactation group, an intense hyperemia occurred immediately after parturition and lasted until 2 days (fig. 5). The capillary hyperemia, however, became gradually mild, but did not completely disappear. From 25 days after parturition, the capiliary hyperemia became intense again (fig. 7).

In the weaning group, an intense capillary hyperemia occurred also immediately after parturition and the capillary hyperemia lasted until later. It was found to be somewhat stronger than in the lactation group. The capillary hyperemia was relatively mild from 17 to 20 days, but later became stronger again.

\section{Discussion}

The normal duration of lactation in female mice has been described to be about 4 weeks (S n e ll, '56). Milk production increases for the first ten days and then gradually decrease ( $\mathrm{Enz}$ m a n n, '33). In lactating mice a long period of diestrus occurs following the first post partum estrus. This diestrus lasts from about 20 to 25 days (C r e w and $\mathrm{M}$ irska i a, ' 30 ; D e a $\mathrm{ns} \mathrm{l} \mathrm{y,} \mathrm{'30).} \mathrm{According} \mathrm{to} \mathrm{T}$ o g a r i ('27), about 20 days following parturition the estrus and ovulation reappear, and from then on the normal estrous cycle is observed. On the basis of these data, the weaning at 25 days after parturition in the present experiment may be considered to be natural and reasonable.

The histological studies including histometrical measurements make it possible to divide the progression of histological changes of the thyroid gland of mice lactating following parturition into the following stages:

1. Shortly after parturition (In puerperium)-the thyroid gland seems to maintain yet a follicular state similar to that found near full term ( $\mathrm{Takeuchi}, 58)$. This stage appears to represent one of increased thyroid activity. The thyroid gland is characterized histologically by microfollicular types and their transitional types, together with the decreased staining of colloid and its strong mar- 
ginal vacuolation (fig. 5). Furthermore, associated with these phenomena, marked swelling and increase in height of the follicle cells with formation of secretory droplets, and strong capillary hyperemia are found (figs. 1, 3, 5 and 10).

A har a ('33) described a similar finding of increased thyroid activity in rats on the second day after parturition; viz., the decrease in size and irregular state of the follicles, the release of colloid and the increase in height and granularity of the follicle epithelium. B e r n a r d (27) revealed the following in dogs: Parturition is followed by the discharge of colloid. After a short time of inactivity, the thyroid gland increases in activity again during the next period of lactation and shows numerous occurrence of vacuoles in the follicle epithelium and strong vacuolation in colloid. S a l te r ('40) also suggested that lactation is one of the circumstances which activates the thyroid glands of man and beast. Z a lesk y ('35) found histologically an increased thyroid activity in lactating ground squirrels.

2. The second stage lasts from 4 to 25 days after parturition. The thyroid gland maintains the same follicular state, microfollicular to transitionally microfollicular types (figs. 1 and 6). The colloid fluctuates in taining to a considerable extent (fig. 3). The follicle epithelium is not so swollen but sometimes increased in height. Secretory droplets are often found. Capillary hyperemia becomes mild. The results are somewhat different from $\mathrm{A}$ h a r a's ('33). He pointed out the gradual increase in size and regular change in shape of the follicles, lesser vacuolation and increasing accumulation of the colloid and reduction of capillary hyperemia in lactating rats from the second to third weeks.

The radioautographic experiments of $\mathrm{Nadler}$ and $\mathrm{B}$ og or o c h ('51) and $\mathrm{N}$ a d l e r, L e b.l o n d and $\mathrm{B} \mathrm{og} \mathrm{or} \mathrm{o} \mathrm{c} \mathrm{h} \mathrm{('54)} \mathrm{revealed} \mathrm{in} \mathrm{rats}$ that thyroid function is accelerated in turnover of thyroglobulin in the smaller follicles. The maintenance of the trend of microfollicular type and the fluctuation in staining of colloid found during the first and second stages may be interpreted as an expression of this acceleration. Furthermore, recent study established a relationship between the formations of secretory droplets in follicle epithelium and thyrotropic hormone in the pituitary. The droplets have been reported to appear after presumably increased endogenous thyrotropic hormone production caused by partial thyroidectomy ( $\mathrm{H}$ ü $\mathrm{r}$ h l e, 1894 ; Is h i$\mathrm{m}$ a r u, '26). In addition, special attention has been directed to the secretory droplets as a basis for thyrotropic hormone assay (De $\mathrm{R}$ o- 
bertis, '42; De Robertis and Del Conte, ' 44 ; D voski n, ' 47 and '48). It seems probable that the frequent occurrence of the droplets during the first and second stages of lactation may have a certain relation with the increased thyrotropic hormone secretion in the pituitary.

3. The third stage appears to consist of three distinct phases, accumulation, storage and gradual decrease of colloid, and seems to be the direct effect of the weaning seen at 26 days after parturition. The thyroid gland is histologically characterized by a rise in frequency per square millimeter of follicles over $50 \mu$, static maintenance of their maximum level and subsequent decrease, with irregular becoming in follicle shape (figs. 1 and 7 ).

The colloid, however, shows for a while a dark staining. Associated with these phenomena, marked capillary hyperemia and swelling of follicle cells (fig. 7), with newly increased formation of secretory droplets, are found. The same presumption of an increased secretion of thyrotropic hormone by the pituitary, as that for the previous stages may be presented to explain this finding.

The thyroid glands of mice who weaned their sucklings immediately after parturition indicated the following two stages.

The first stage lasts from immediately after parturition to 16 days and reveals a finding similar to that found in the puerperium and in the subsequent stage of the lactation group. The thyroid gland appears microfollicular and transitionally microfollicular with an irregular change of follicle shape and furthermore with dark staining of colloid (figs. 2, 4 and 8). The formation of secretory droplets in the follicle epithelium is less frequent (figs. 2 and 4).

The second stage lasts from 17 days after parturition to 30 days, and reveals a rise, maintenance of high values and subsequent decline in frequency of follicles over $50 \mu$, with some exceptions. This is similar in histological pattern to the third stage of the lactation group. The swelling of the follicle cells occurs with an increased formation of secretory droplets.

Apparently there is a time relation concerning the changes observed in the lactation and weaning groups. In the lactation group, the lactation is maintained almost in a natural condition and the sucklings are weaned also almost in a natural condition. A transient increase in frequency per square millimeter of follicles over $50 \mu$ at 26 to 33 days after parturition is distinctly considered as the direct effect of weaning (fig. 1). On the other hand, a direct effect is not 
distinct in the weaning group. Instead of this, the gland shows a transient rise in the frequency of the follicles over $50 \mu$ at 17 to 25 days (fig. 2). What does this mean?

Another point of interest is the following: Despite the similarity of the follicular trend in the initial stages, there is shown some histological difference between the lactation and weaning groups. In the lactation group, there is a marked occurrence of secretory droplets in the follicle epithelium, while in the weaning group a decrease in occurrence is seen (figs. 1 to 4).

Recent study has revealed some variations in thyroid function during the sexual cycle. Lee ('27; '28) described a significant increase in the basal metabolic rate of the female rat during the last 10 hours of the diestrus and the first 6 hours of the proestrus. According to Reineke and Soliman ('53), the oxygen consumption showed a significant rise during the estrus of female rats. In the course of the sexual cycle, definite changes have been reported to occur in iodine metabolism. During estrus there is a decreased iodine content in the thyroid gland of rats $(\mathrm{Nakamura}, 32)$. In goats, Leitch and Henderson ('26) found a hyperiodemia in heat. Reineke and Soliman ('53) described that there is a significantly greater collection of $\mathrm{I}^{131}$ by the thyroid gland of rats during the estrus than in any of the other stages. However, at the same time both authors stated for female mice that the rise in $I^{131}$ uptake starts during the diestrus and reached a peak during the proestrus rather than during the estrus. Feld man ('56) reported also an increase of $I^{131}$ uptake by the thyroid gland during the estrus of rats. On the other hand, no cyclic change is found in the thyroid gland of women by measuring the $I^{131}$ uptake ( $\mathrm{S} \mathrm{u} \mathrm{zu} \mathrm{k} \mathrm{i}$, '57). According to Turner and Cupps ('39), the assay for thyrotropic hormone on the pituitary of estrous rats is very low. The results are slightly variable according to the species of animals used.

Histological studies of the thyroid glands in relation to the sexual cycle revealed the following: $\mathrm{Hunt}$ ('44) observed in young rats that the mitotic activity of the gland increased slightly in early estrus, reached a maximum during the estrus, declined during the metestrus and became minimal during the diestrous interval. Chouke, Friedman and Loeb ('35) pointed out the mitotic cycle of the thyroid gland in relation to the sexual cycle in guinea pigs. N a k a m r a ('32) pointed out the abundant accumulation of colloid during the estrus of rats. According to Perri ('37), the 
flattening of the follicle epithelium occurs from the 11th day of the cycle in guinea pigs. In the estrous stage provoked by giving Prolan, the storage type is found in the thyroid gland of foxes (Solove $\mathrm{y}$ and $\mathrm{Kak}$ a s hina, '37).

The present data show considerable variability and suggest that the thyroid gland of mice seem to reveal no significant histological change in relation to the sexual cycle. However, the gland shows on the average a slight decrease in size of the general follicles in diestrus, and a slight decrease in staining of general colloid in estrus and metestrus (tables 1 and 2). No mitotic cycle was found. The prevailing occurrence of secretory droplets in the follicle epithelium was also found in every stage of the sexual cycle (tables 1 and 2).

Near or at the reappearance of the normal sexual.cycle after parturition, no characteristic histological changes were observed in the lactation and weaning groups (figs. 1 to 4 , and tables 1 and 2).

\section{Summary}

A total of 249 primiparous mice were used for histological studies of the thyroid gland of mice in relation to lactation, weaning and the sexual cycle. The animals were divided into two groups of lactation and weaning. The lactation group consisted of mother mice who nursed 4 sucklings up to 25 days after parturition and weaned at the $\mathrm{e}_{i}$ 26th day. The weaning group consisted of mother mice who were forced to wean immediately after parturition. In both groups, the vaginal smear test was made on mice who weaned their sucklings.

In the lactation group-Immediately after parturition, the thyroid gland shows a microfollicular trend, feeble staining and much vacuolation of colloid and swelling of follicle epithelium with increased formation of secretory droplets. Subsequently, the gland indicates almost the same state until weaning. Immediately after weaning, the gland shows for a while a transient increase in size of follicles (macrofollicular trend), and swelling of follicle epithelium with newly increased formation of secretory droplets.

In the weaning group-The thyroid gland shows a finding similar to that found in the early period of the lactation group. The formation of secretory droplets in the follicle epithelium, however, is less frequent. From 17 days after parturition, the gland shows for a while a transient increase in size of follicles and swelling of the follicle epithelium with increased formation of secretory droplets. 
The thyroid gland shows histologically no significant changes in relation to the sexual cycle. The gland, however, shows on the average a slight decrease in size of follicles in diestrus, and a slight decrease in staining of colloid in estrus and metestrus.

\section{Literature Cited}

A h a r a, M.: Studien über die Golgischen Apparate der Schilddrüsenzellen. I. Über die Veränderungen der Golgischen Apparate der Schilddrüsenzellen während des oestrischen Zyklus und nach der Kastration. Mitt. med. Akd. Kioto, 8: 361394, 1933 (Japanese).

- : Studien über die Golgischen Apparate der Schilddrüsenzellen. II. Über die Golgischen Apparate der Schilddrüsenzellen während der Schwangerschaft, Geburt und Laktation und ihre funktionelle Bedeutung. Mitt. med. Akad. Kioto, 8: 381-394, 1933 (Japanese).

A ron, M.: Particularites histologiques de la reaction de la thyroide aux extraits de lobe anterieur d'hypophyse. C. R. Soc. Biol. Paris, 103: 145-147, 1930.

- Les tests morphologiques du fonctionnement thyroidien. C. R. Ass. Anat., $29: 7-22,1934$.

B a r g m a n n, W.: Die Schilddrüse in v. Möllendorff's Handb. mikr. Anat., 6: 2 T1., 1-136, Julius Springer, Berlin., 1939.

Bernard, W.: La thyroide au cours de la grossesse. Rev. Franc. d'Endocrin., 5 : 395-452, 1927:

Chouke, K.S., H. Friedman and L. Loeb: Proliferative activity of the thyroid gland of the female guinea pig during the sexual cycle. Anat. Rec., 63: 131137, 1935.

Crew, F.A.E. and L. Mirskaia: The lactation interval in the mouse. Quart. J. Exp. Physiol., 20 : 105-110, 1930.

Deanesly, R.: The corpora lutea of the mouse, with special reference to fat accumulation during the oestrous cycle. Proc. Roy. Soc. B., 106:578-595, 1930.

De Robertis, E.: Anat. Rec., 84: 125, 1942 (cited by Dvoskin, '47).

De Robertis, E. and E. Del Conte: Rev. Soc. Argent. Biol., Biol., 20: 88, 1944 (cited by Dvoskin, '47).

Dragstedt, L.R.A., C. Sud a n and K. Phillips: Studies on the pathogenesis of teteny. IV. The teteny of oestrus, pregnancy and lactation. Am. J. Physiol., $69: 477-497,1924$.

Dvoskin, S.: Intracellular colloid droplets as a basis for thyrotrophic hormone in the chick. Endocrin., 41:220-229, 1947.

- The effects of pituitary and non-pituitary gland factors on the formation of intracellular colloid droplets in the thyroid epithelium of hypophysectomized rats. Endocrin., $43: 52-70,1948$.

En $z$ mann, E.V.: Milk-production curve of albino mouse. Anat. Rec., 56:345-358, 1933.

Feldman, J.D.: Effect of estrus and estrogen on thyroid uptake of I $^{181}$ in rats. Endocrin., 58: 327-337, 1956.

Folley, S. J.: Experiments on the relation between the thyroid gland and lactation in the rat. J. Physiol., 93: 401-412, 1938.

Florentin, P., Th. Fontaine et L. Hennequin: Modifications de la glande 
thyroide consecutives a la gangliectomie cervicale superieure chez le lapin. C. R. Soc. Biol. Paris, 121 : 1410-1412, 1936.

Gr a h a m, W. R. : The effect of thyroidectomy and thyroid feeding on the milk secretion and milk fat production of cows. J. Nutrit., 7: 407-429, 1934 a.

- : The action of thyroxine on the milk and milk-fat production of cows. Biochem. J., 28 : 1368-1371, 1934 b.

Grimmer, W.: Beiträge zur Kenntnis der Milch Schilddrüsenlosziegen. Biochem. Z., 88: 43-52, 1918.

Hunt, T.D.: Mitotic activity in the thyroid gland of female rats. Anat. Rec., 90 : 133-138, 1944.

H ü r thle,K.: Beiträge zur Kenntnis des Sekretionsvorgänges in der Schilddrüse. Pflüger's Arch., 56 : 1-44, 1894.

I s h i m a r u, S.: Über den Golgi-Apparat in den Schiddrüsenzellen. Okajimas Fol. anat. jap., $4: 13-32,1926$.

J a ckson, C. M.: Effects of inanition upon the structure of the thyroid and parathyroid glands of the albino rat. Am. J. Anat., 19: 305-352, 1916.

$\mathrm{Krog} \mathrm{h}, \mathrm{M}$. and $\mathrm{H}$. Okkels : Quelques resultats recents de l'histophysiologie thy. roidienne. Bull. Histol. appl. $10: 105-112,1933$.

L e e, M. O.: Basal metabolism in the rat during the oestrous cycle. Am. J. Physiol., 81 : 492-493, 1927.

- : Studies on the oestrous cycle in the rat. IV. The basal metabolism during the oestrous cycle. Am. J. Physiol., 86: 694-705, 1928.

Le it ch, I. and J. McA. Henders on: The estimation of iodine in foodstuffs and body fluids. Biochem. J., $20: 1003-1007,1926$.

$\mathrm{Nad}$ le r, N. J. and R. B o g o r o ch: Quantitative estimation of radioautographic reactions of thyroid follicles. Anat. Rec., 109: 329, 1951.

Nadler, N. J., C.P. Le blond and R. Bog or och: The rate of iodine metabolism by the thyroid follicle as a function of its size. Endocrin., 54:154-172, 1954.

Nakamura, U.: The sexual cycle and the thyroid gland. I. The histological change of the thyroid gland of the rat during the sexual cycle. Jap. J. Obst. and Gynec., 15 : 1131-1143, 1932.

- : The sexual cycle and the thyroid gland. II. The sexual cycle and the iodine content of the thyroid gland. Jap. J. Obst. and Gynec., 15: 1144-1151, 1932.

Nels o n, W.O.: Endocrine control of the mammary gland. Physiol. Rev., 16: 488$526,1936$.

Nel s o n, W. O. and C.E. Tobi n: Studies on the physiology of lactation. VII. Lactation in thyroidectomized rats and guinea pigs. Endocrin., $21: 670-676,1937$.

$\mathrm{Oh}$ ida, S.: Histological studies of the thyroid gland of the mouse after castration. Okajimas Fol. anat. jap., $26: 347-370,1954$.

Per ri, T.: Ricerche sulle modificazioni istologiche della tiroide nella cavia durante il ciclo dell'estro. Att. R. Accad. naz. Lincei, VI s. 25, 742-746, 1937.

Reineke, E.P. and F.A. Soliman: Role of thyroid hormone in reproductive physiology of the female. Iowa State Coll. J. Sci., 28: 67-82, 1953.

S a lt e r, W. T.: The endocrine function of iodine. 1-351, Harvard Univ. Press, Cambridge, 1940.

Severinghaus, A. E.: Cytological observations on secretion in normal and activated thyroids. Z. Zellforsch., $19: 653-680,1933$.

S ne 11, G. D.: Biology of the laboratory mouse. 1-497, Dover Public. Inc., New York, 1956.

Solovey, M.J. and E.A. Kakushkina: Interaction between the genital and 
thyroid glands in the experimental sexual cycle. Bull. Biol. et Med. exper. U. R.S.S., 4 : 499-501, 1937.

Sugi y a ma, S.: The morphogenetic and histogenetic studies of the thyroid gland of the albino rat. Nagoya Igakkai Zasshi, $50: 1171-1246,1939$ (Japanese).

Sugi yama, S. and T. Sato: Studies of the histogensis of the thyroid gland of the guinea pig. II. Quantitative measurements of the follicles and correlation with function. Anat. Rec., 120 : 379-394, 1954.

Sugiyama, S. and T. Yagizawa: On the postnatal histogenesis of the thyroid gland of the rabbit. 3. On the thyroid function researched from the histogenetic point of view. Okajimas Fol. anat. jap., 23: 67-79, 1950.

Su z uki, B.: Relationship between thyroid function by [131-uptake and menstrual cycle. Jap. J. Fert. Ster., 2: 27-37, 1957.

Take u chi, K.: Histological studies of the thyroid gland of the mouse during pregnancy. Okajimas Fol. anat. jap., 32: 1958.

Tog a ri, Ch.: On the ovulation of the mouse. Nagoya J. Med. Sci., 11: 17-50, 1927.

Turner, C.W. and P.T. Cupps: The thyrotropic hormone in the pituitary of the albino rat during growth, pregnancy and lactation. Endocrin., 24: 650-655, 1939.

Weichert, C. K. and R.W. Boyd: Stimulation of mammary gland development in the pregnant rat under condition of experimental hyperthyroidism. Anat. Rec., 59: 157-186, 1934.

Z a le sky, M.: A study of the seasonal changes in the thyroid gland of the thirteenlined ground squirrel (Citellus tridecemlineatus), with particular reference to its sexual cycle. Anat. Rec., 62: 109-137, 1935.

\section{Explanation of Plate Figures}

All figures represent photomicrographs of transverse sections of thyroid lobes fixed in Ciaccio's fluid and stained with Heidenhain's iron hematoxylin. Note: F : Frequency averaged per square millimeter of follicles over $50 \mu$; : Frequency averaged per square millimeter of irregular-shaped follicles; P: Percentages averaged per field (ocular $\times 8$; objective $\times 40$ ) of the number of follicles containing darkly stained colloid.

5. Lactation group Immediately after parturition

Transitionally microfollicular type (F: $56 ;$ f: $14 ;$ P: $47 \%) \times 70$.

6. Lactation group 22 days after parturition Microfollicular type $(F: 25 ;$ f : $16 ; P: 64 \%) \times 70$.

7. Lactation group 28 days after parturition Transitionally macrofollicular type (F: $99 ; \mathrm{f}: 53 ; \mathrm{P}: 93 \%) \times 70$.

8. Weaning group 6 days after parturition Transitionally microfollicular type (F: $58 ; \mathrm{f}: 27 ; \mathrm{P}: 78 \%) \times 70$.

9. Weaning group 20 days after parturition Transitionally macrofollicular type (F: $85 ; \mathrm{f}: 33 ; \mathrm{P}: 80 \%) \times 70$.

10. Lactation group Immediately after parturition Transitionally microfollicular type $(F: 67 ; f: 10 ; P: 63 \%)$ Numerous secretory droplets are found in follicle epithelium. $\times 800$. 
Plate 1

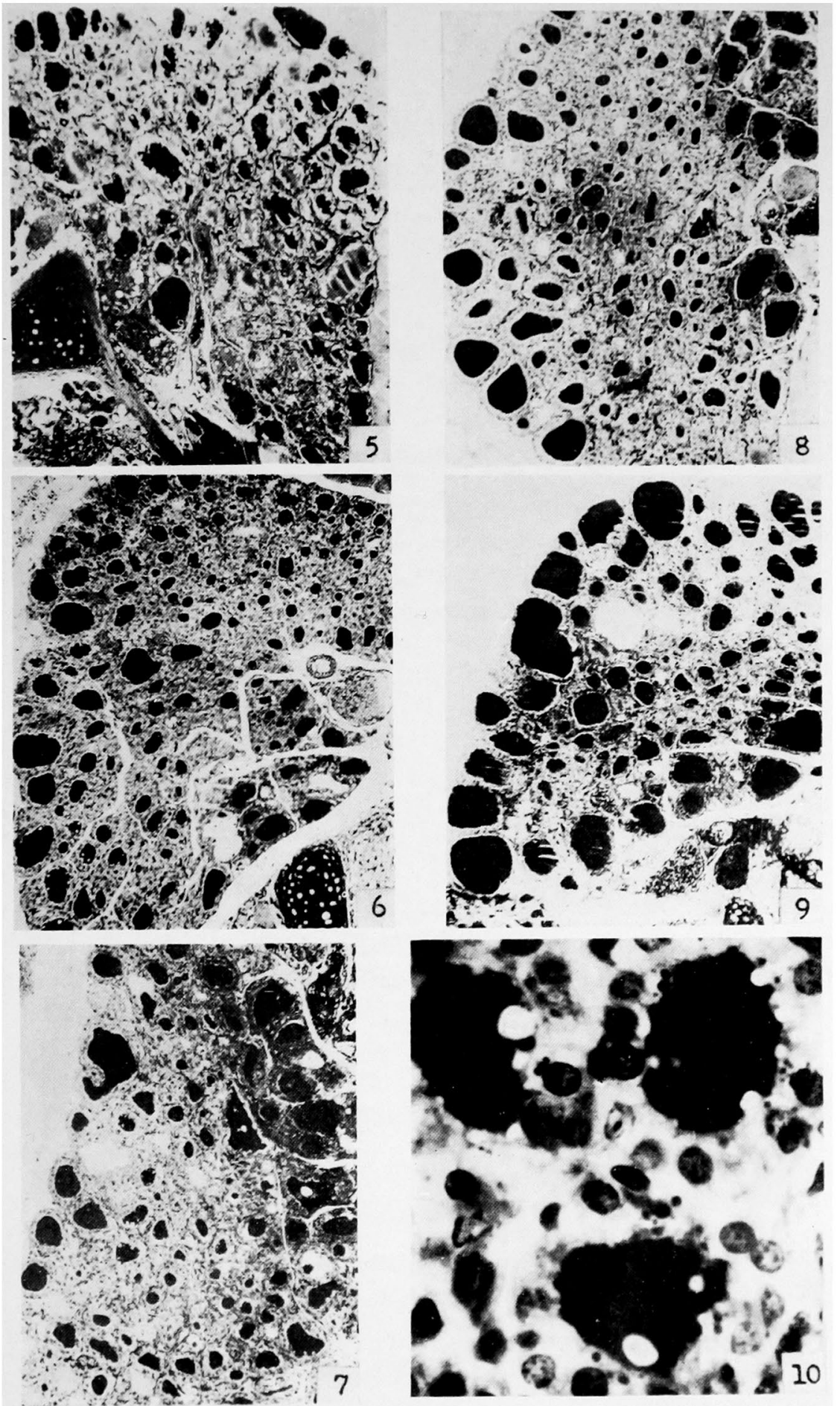

Y. Aida 